\title{
Using Building Information Modeling as a Tool for Project Scheduling and Data Management
}

\author{
Ya-bo $\mathrm{HE}^{1}$, Tao XU ${ }^{1}$, Qing-da $\mathrm{LI}^{2}$, and Xin $\mathrm{ZHAO}^{2, *}$ \\ ${ }^{1}$ School of Civil Engineering, Wuhan University, No.8 East Lake South Road, Wuhan, China \\ ${ }^{2}$ China Construction Third Engineering Bureau Group Co., LTD, FA10 International Commerce \\ Center 69\# Banjing Road, Haidian District, Beijing, China
}

${ }^{*}$ Corresponding author

Keywords: Building Information Modeling (BIM); Project Scheduling; BIM 4D; Data Management.

\begin{abstract}
Proponents of building information modeling (BIM) enthusiastically tout as one of its advantages its ability to work in conjunction with other software programs to predict the performance of buildings. Theoretically this would help in the scheduling process of buildings. This paper summarized the method of directly using BIM as a tool to make project's schedule based on information a BIM model provides. It introduces how to use a BIM model to manage schedule tasks, use quantities and location information from it, and manage productivity data for scheduling. By using BIM model based scheduling process, the BIM model can be a platform to document and manage the actual procedure data, which can be valuable for future projects.
\end{abstract}

\section{Introduction}

BIM 4D is referred to the fourth dimension: time, which is 3D plus schedule [1]. The traditional workflow of BIM 4D is using scheduling software to create and update the schedule and then link the tasks from the schedule to the BIM model [2]. It allows the project team to simulate and evaluate the planned construction sequence, analyzing coordination between different trades and distribution of different resources.

However, in traditional BIM 4D workflow, BIM is not acting as a tool of scheduling, it serves as a tool to determine if the schedule is optimized after the schedule is finished. Moreover, the project information from the BIM model is not used during the scheduling process, linking schedule to BIM not only costs project team's extra time, but also make the decision making process lagging.

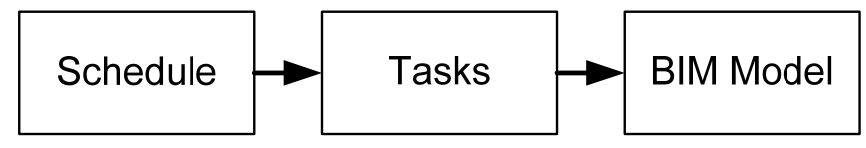

a.Traditional BIM 4D work flow

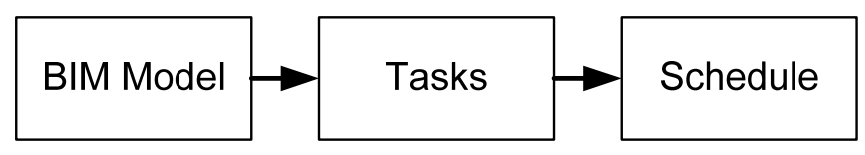

b. Using BIM as A Tool for Scheduling

Fig. 1. Comparison of two BIM 4D workflow

Scheduling is the management process of tasks which are specified and assigned to resources that complete the work [3]. A major aspect of scheduling process is to determine the tasks and duration of them,during execution, actual performance will be input to keep the schedules on track. As BIM is an integrated process for exploring a project's key physical and functional characteristics digitally before it is built [4]. It can be regarded as a virtual building model that contains the necessary information to predict the behavior of a building while it is still in digital format. So instead of linking schedule to model, it is possible to directly use BIM for scheduling: using the information from a 
BIM model to determine and create tasks, calculating the duration based on the resources from BIM, and using BIM as platform to track the schedule and coordinate different participants, managing the data collected during schedule execution process.

This paper will research and show a different BIM 4D method, which using BIM as tool for scheduling and data management. The method can be applied to any BIM and schedule program with add-on development, and can also be applied to manage different project data type.

\section{Research Design and Method}

Depending on the information needs during a project scheduling and characters of BIM model, a four-step, reiterative research strategy was designed to identify the new BIM 4D process, the detail scheduling process will not be discussed in research. Firstly, determine what information is needed during a project's scheduling, and what information can be obtained from a BIM model. Step 2 is determining how to match the BIM element classification systems with a schedule's work breakdown system, in which case to make BIM model to generate schedule tasks and deliver the information from BIM model to tasks. This step will also use productivity data as an example to determine the possibility to keep the model as a single source of all schedule information. Step 3 is to research how to take the advantage of data recorded during scheduling, make the data more useful for decision makings for similar projects in future. Finally, a case study is engaged to illustrate the process of using BIM as tool for an actual project's scheduling and productivity data management.

\section{Information delivery From BIM Model to Schedule}

A schedule as a basic project time-management tool, consists of a list of times at which possible tasks or activities are intended to take place, or of a sequence of tasks in the chronological order in which such things are intended to take place [5]. So information required by scheduling includes tasks, duration, and sequence of tasks. A task is decided by the material or activity that composed the project. And the duration of a task is calculated by the workload and resources that will put into. The sequence of tasks follows the project process, which is defined as logics between tasks in scheduling.

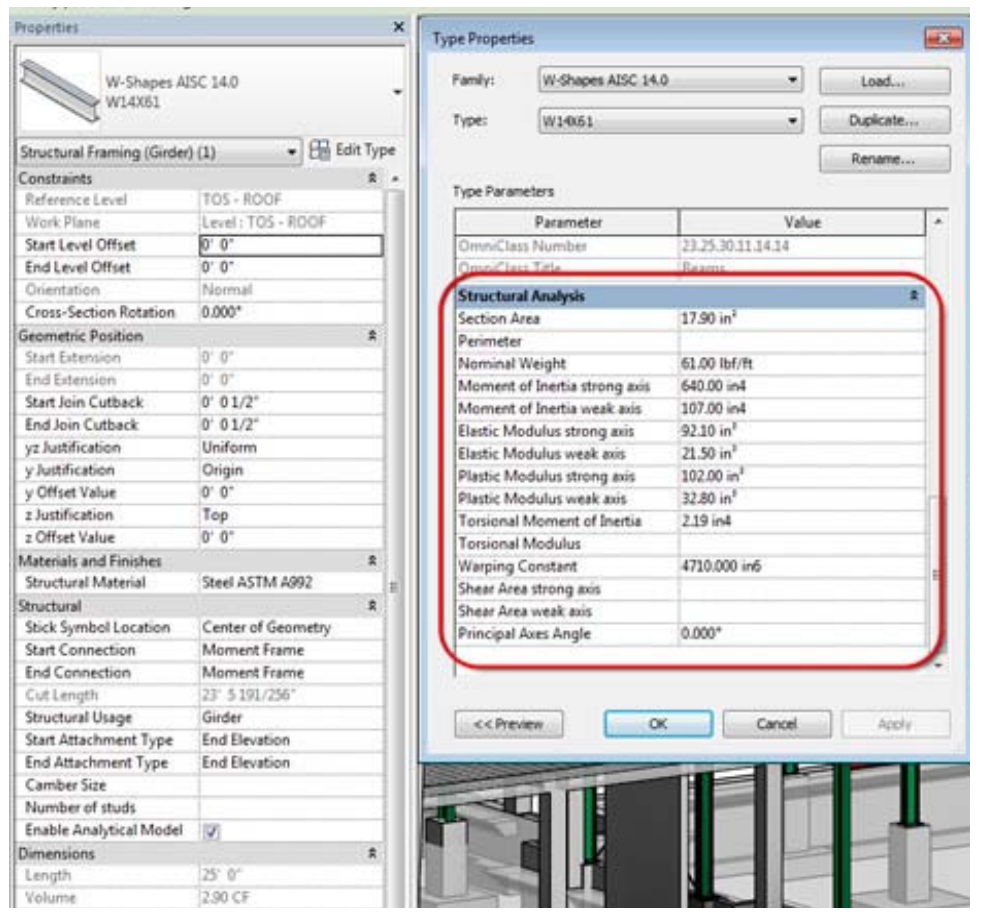

Fig. 2. An element's information in a BIM modeling software 
A BIM model contains the necessary information of a building in digital format. Take Revit for example, through a BIM model, information a scheduler can get includes a building element's name, type, material, geometry, location classification, manufacturer or trade, etc., (Figure 2). Those information can meet basis that a schedule requires. However, when a BIM model is delivered from one functional BIM software to the other, most information usually will get lost, including materials or activities (Figure 3). Although buildingSMART developed Industry Foundation Classes (IFC) data model to describe and deliver building and construction industry data, the IFCs are not intended to store and carry all relevant data for all multi-featured project processes. Furthermore, not all relevant data can be structured in a single super schema.

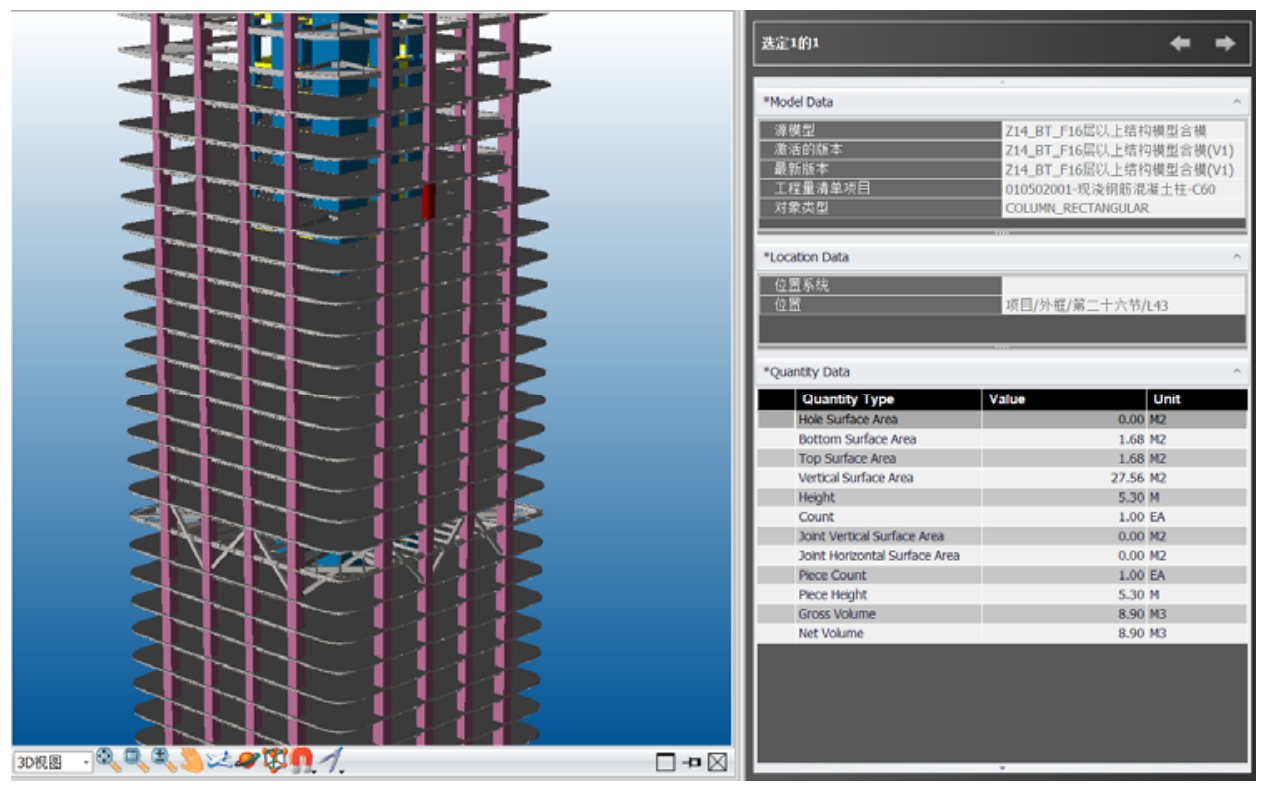

Fig. 3. An Element's information after exporting to scheduling software

For most BIM platforms in industry, when import a BIM model from modeling software to scheduling software, an element will have naming, geometry, location and classification information be delivered. So for using BIM as a scheduling tool, a scheduler can take advantages of those information. Table 1 shows how to match the information needed during scheduling with a BIM model.

Table 1. Matching the information needed during scheduling with a BIM model

\begin{tabular}{|c|c|c|c|}
\hline \multicolumn{2}{|c|}{ Schedules } & \multicolumn{2}{c|}{ Bodel } \\
Information Needed & Functions & Information Output \\
\hline Activity & Determine schedule task & Model element & $\begin{array}{c}\text { Model element's naming } \\
\text { and classification }\end{array}$ \\
\hline Quantities & Determine workload & Model element & $\begin{array}{c}\text { Model element's } \\
\text { geometry }\end{array}$ \\
\hline Productivity & Determine duration & $/$ & $/$ \\
\hline Location & $\begin{array}{c}\text { Determine location a task } \\
\text { take place and optimize } \\
\text { resources distribution }\end{array}$ & Location system & $\begin{array}{c}\text { Location information, or } \\
\text { define location } \\
\text { information in schedule } \\
\text { software }\end{array}$ \\
\hline Logics & $\begin{array}{c}\text { Determine relationships } \\
\text { between tasks }\end{array}$ & $/$ & \begin{tabular}{c}
$/$ \\
\hline
\end{tabular} \\
\hline
\end{tabular}

By using the information from a BIM model, project team can quickly read the information that is needed for scheduling from design, which can help the decision making during scheduling more timely and precisely. And when design changes, the information changes can directly reflect in BIM 
a model. Moreover, work on the BIM platform and benefit from a highly coordinated and integrated project across the project process while sharing meaningful building information directly between applications.

\section{BIM Classification System and Scheduling Work Breakdown Structure}

A BIM model helps a scheduler quickly obtain the project's key information for scheduling, to make the information as a part of a schedule's task, it is possible to deliver the information from BIM to schedule by restructure the work breakdown structure and classification system.

A work breakdown structure (WBS) in project scheduling is used to decompose a project into smaller components. A WBS is a project's key deliverable that organizes the team's work into manageable sections [6]. A WBS element may be an activity, service, or any combination. For a BIM model, classification system is fundamental to achieving effective information management. It divides BIM model components into groups which helps managing a vast quantity of data or information. In traditional BIM 4D workflow, the BIM model elements will be grouped and organized to match with the schedule tasks, and the model elements are identified by the naming convention, or by the matching with BIM classification system with the schedule work breakdown system.

The most two popular classification systems in AEC industry are MasterFormat and UniFormat. MasterFormat provides a master list of titles and section numbers for organizing data about construction requirements, products, and activities. While UniFormat organizes construction information based on the building's major systems and functional elements. Information includes preliminary project descriptions, performance specifications, facility management, cost estimating and analysis, drawing details, BIM objects, and construction market data.

\section{Concrete \\ $031100 \quad$ Concrete Forming \\ 032000 Concrete Reinforcing \\ 033000 Cast-in-Place Concrete}

Fig. 4. Comparison of MasterFormat (left) with UniFormat (right)

From the features of two classification systems, it can be determined that Master Format is based on material and activity, so it can be used as a scheduling WBS. UniFormat is based on elements and object, so it's widely used in identifying BIM models. Other popular classification systems in industry, such as OmniClass and UniClass, are similar with the Master Format and UniFormat, either driven by material or elements. However, for the most popular BIM modeling software in industry, a BIM model is usually based on element and object, and modeler defines materials or activities in it. So from a BIM model, schedule task of a project cannot directly taken from a BIM model.

\begin{tabular}{|c|c|c|}
\hline Level 1 & \multicolumn{2}{|c|}{ Element Based Classification } \\
\hline & Level 2 & Activity Based Classification \\
\hline & Level 2 & Activity Based Classification \\
\hline & Level 2 & Activity Based Classification \\
\hline
\end{tabular}

$\cdots$ 
Fig. 5. Hierarchy of classification

Creating a hierarchy classification system will be a solution for BIM model. As figure 5 shows, using an element based classification for a BIM model object as an upper level, and classify materials and activities associate with the typical element as a lower classification. Take continuous footings as an example (figure 6), they are independent elements in a BIM model, by defining lower level classifications under it, the model element can be divided into materials and activities which can also be treated as tasks in schedule which can be used for work breakdown system. In this case, the tasks will be 'assemblies' of typical building objects.

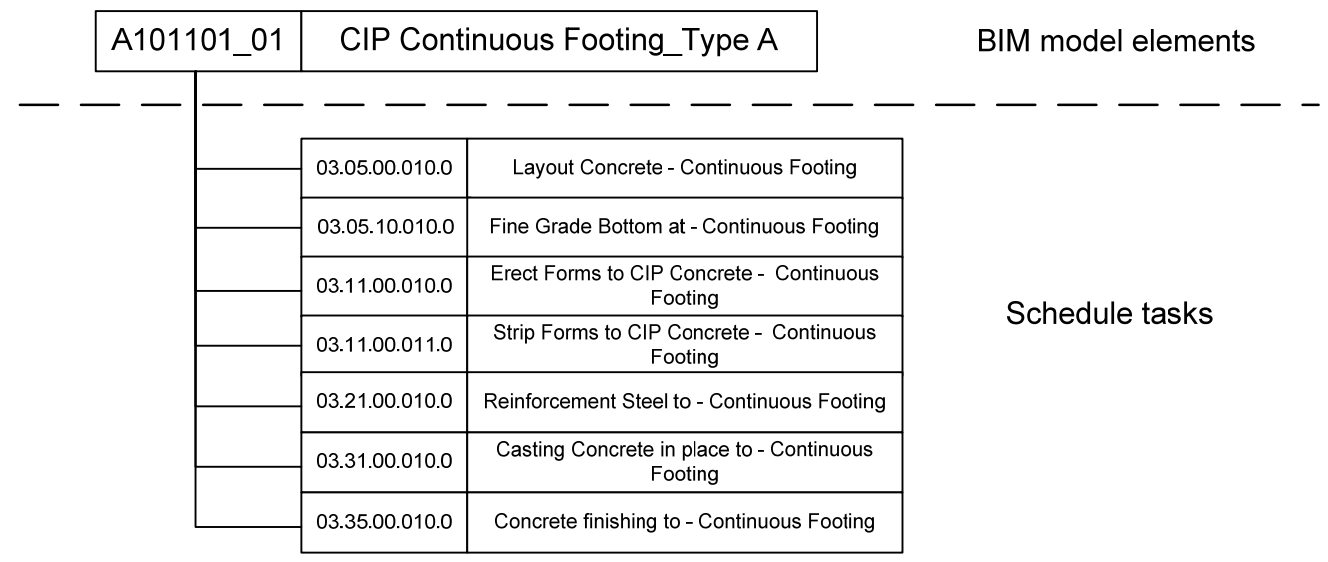

Fig. 6. Example of a hierarchical classification

Most scheduling software contains a library for work breakdown systems which can used for generating schedule tasks. In a good traditional 4D workflow, model elements will be grouped and linked with schedule tasks according to WBS, model elements will be linked repeatedly to different tasks as elements contains different materials and activity, and using color code to distinguish them [7]. By the new 4D workflow, a project team can exchange the model information classification through the 4D entry of schedule software, by matching the hierarchy classification system to generate the schedule tasks which contains the building information, helping with better decision making during scheduling.

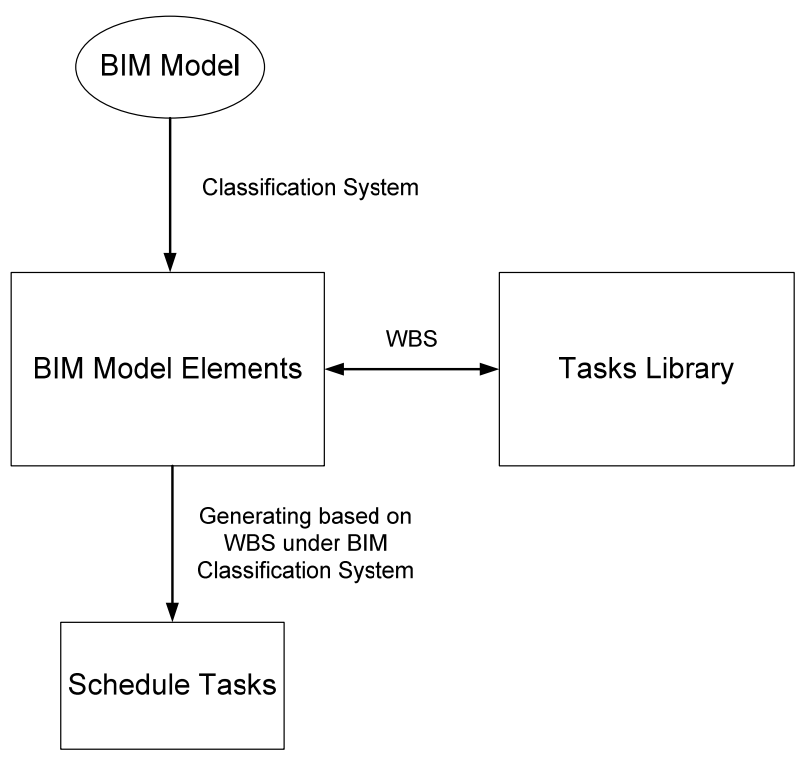


Fig. 7. Process of using BIM model to generate schedule tasks

\section{Data Management based on BIM}

By using BIM as a tool for scheduling, BIM is severing as a platform to record the project data collected during execution. In BIM data platform, building components will embed intelligence and communication capability by an ID based on calcification system, components assembled into buildings will have aggregate intelligence greater than the individual parts [8].

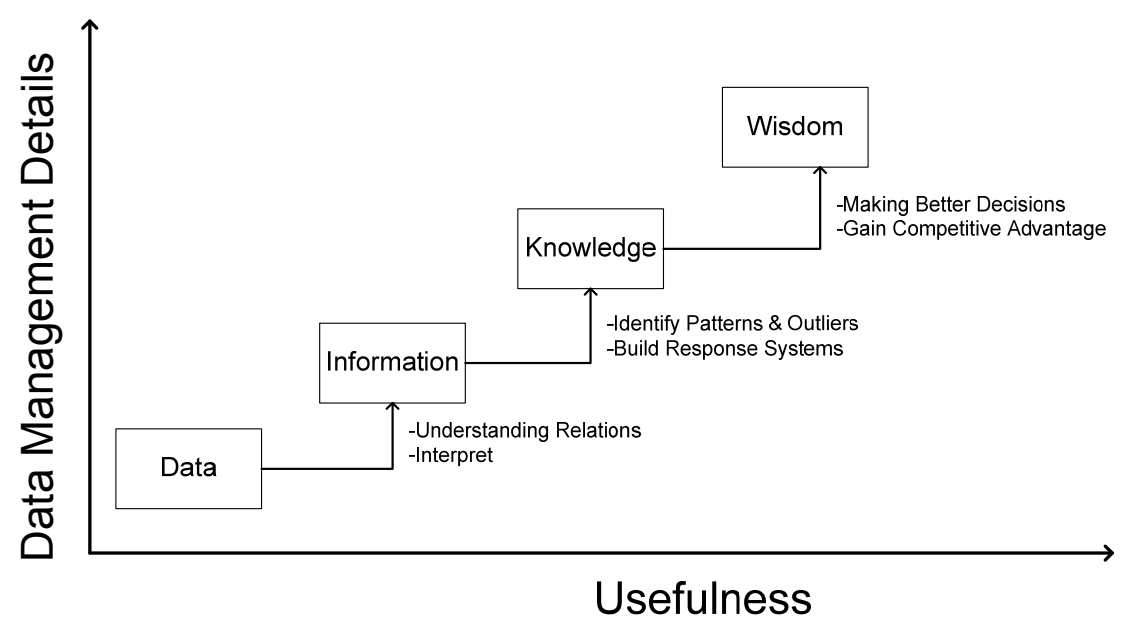

Fig. 8. Different levels of data management

Take productivity data for example, the productivity rate that a scheduler used during scheduling is an experience data which is static. However, this value can be varied under different situation, in construction stage, a real productivity rate needs to be recorded to predict the tendency of project. As a building element is identified with a classification system, it will serve as an ID for a typical element, and real productivity rate of activities associate with the element can be recorded under this ID, which make the model as a productivity database. As BIM encompass the entire productivity data of the building, this makes it possible to determine how a similar project in future will behave before actual construction, forecast and avoid schedule delay risks in advance. And by setting a criteria, it is also possible to make the data as 'smart' as automatic scheduling and risk notification.

The classification can also be used to document all types of data for a project. This approach greatly facilitates future building management activities, because the BIM model stores all the building technology elements along with all associated technical data for different disciplines. In the future, technicians will be able to access the building's BIM to find all the data and documentation about its lifecycle process.

\section{Case Studies}

Project Background. Z14 towers project is located in the core area of CBD in Beijing. The north tower building will be constructed as the center building for world Chinese merchants, and the south tower building is drafted to be the headquarter building of Charoen Pokphand Group. The total building area is $316,000 \mathrm{~m} 2$, both towers are 45 stories and 238 meters tall. The structure form of this project is reinforced concrete core-tube with steel reinforced concrete frame.

Workflow of scheduling. In this project, the architect provides the BIM model to the contractor, and the contractor is using Vico Office for construction management. Vico Office is an integrated BIM platform which is designed for construction management, it contains an independent software called Schedule Planner which allows contractor to make schedule in it. 
The traditional workflow of Vico's 4D needs linking models to tasks before or after scheduling process. Instead of separating scheduling and BIM 4D workflow, the project team directly use architect's model to generate project task, and make project schedule based on BIM model information and resources. And by add-on function's development, the project team use the BIM model to manage the data input during scheduling execution process.

In this project, the project team use the enterprise classification system to classify the BIM model elements, and use the enterprise WBS system to define schedule tasks. As figure 11 shows, the WBS system is a subclass of BIM classification system, so when import the BIM model to scheduling BIM platform, it will recognized the elements and automatically generated tasks based on classification system and subclass WBS system. With the incorporation of tasks, locations, quantities information from BIM model, project team can add productivity rates, resources plan and logic to adjust schedules and predict finish date.

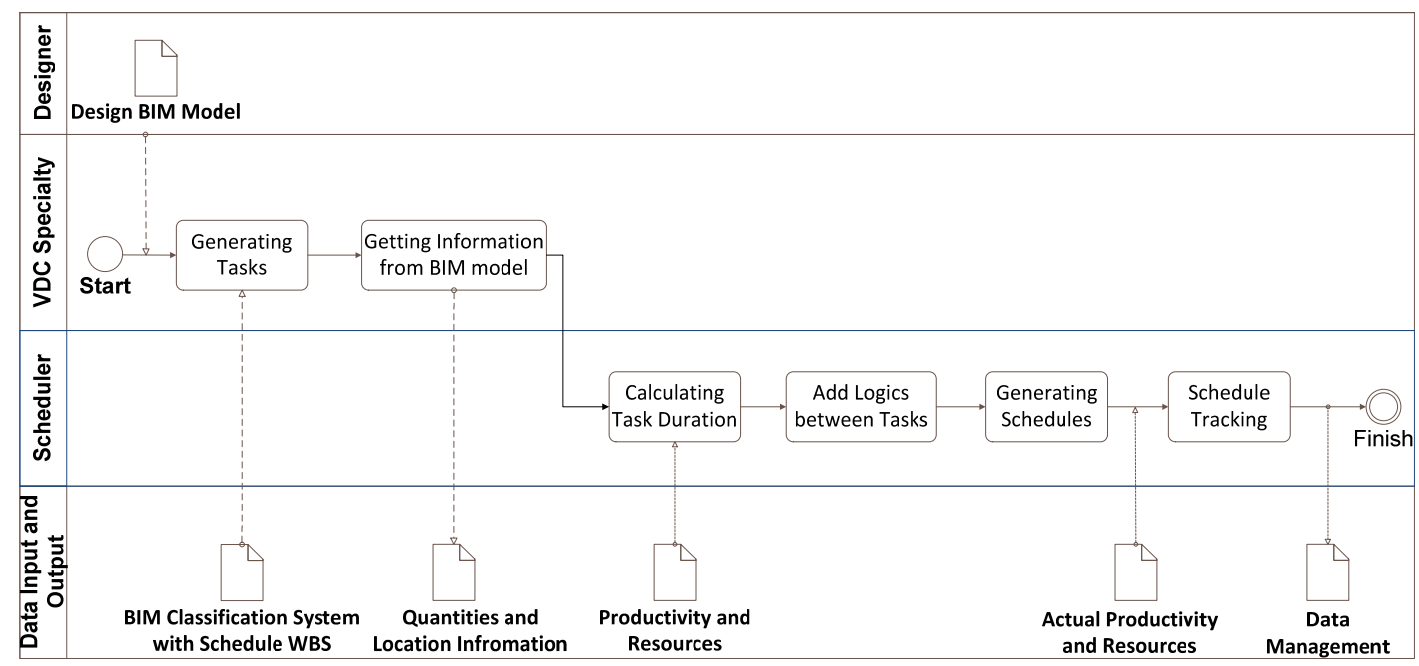

Fig. 9. Workflow of Scheduling

\begin{tabular}{|c|c|c|c|c|c|c|}
\hline ZJSJBJGS-001 & Z14-CSCEC-BT-Schedule & 1.00 & 1.000 & 1.000 & 1.000 & 1.00 \\
\hline -BT & North Tower & 1.00 & 1.000 & 1.000 & 1.000 & $1.00-$ \\
\hline$-A 00$ & Superstructure & 1.00 & 1.000 & 1.000 & 1.000 & $1.00-$ \\
\hline -A-ST & Main Structure & 1.00 & 1.000 & 1.000 & 1.000 & $1.00-$ \\
\hline -A-ST-20.03.00 & A-ST-20.03.00-Core Tube Slab & $6,393.64$ & 1.000 & 1.000 & 1.000 & $6,393.64 \mathrm{m3}$ \\
\hline$-01 \mathrm{~T} 104020302$ & Core Tube Slab-Concrete & $1,127.02$ & 1.000 & 1.000 & 1.000 & $1,127.02 \mathrm{m3}$ \\
\hline 870011 & work dav & $1,127.02$ & 0.384 & 2.604 & 1.000 & $432.78 \mathrm{HR}$ \\
\hline$-01 \mathrm{~T} 104020102$ & Core Tube Slab-Formwork & $2,631.58$ & 1.000 & 1.000 & 1.000 & $2,631.58 \mathrm{m2}$ \\
\hline 870013 & work dav & $2,631.58$ & 0.331 & 3.021 & 1.000 & $871.05 \mathrm{HR}$ \\
\hline$-01 \mathrm{~T} 104020202$ & Core Tube Slab-Rebar & 112.70 & 1.000 & 1.000 & 1.000 & $112.70 \mathrm{~m} 2$ \\
\hline$1 \longdiv { 8 7 0 0 1 2 }$ & work dav & 112.70 & 0.386 & 2.591 & 1.000 & $43.50 \mathrm{HR}$ \\
\hline A-ST-20.03.06 & A-ST-20.03.06-Frame Truss Deck & $6,393.64$ & 1.000 & 1.000 & 1.000 & $6,393.64 \mathrm{~m} 2$ \\
\hline$-01 \mathrm{~T} 10402030901$ & Frame Truss Deck-Installation & $52,665.94$ & 1.000 & 1.000 & 1.000 & $52,665.94 \mathrm{~m} 2$ \\
\hline 870031 & work dav & $52,665.94$ & 0.167 & 5.988 & 1.000 & $8,795.21 \mathrm{HR}$ \\
\hline$-01 \mathrm{~T} 10402010303$ & Frame Truss Deck-Concrete & $52,665.94$ & 1.000 & 1.000 & 1.000 & $52,665.94 \mathrm{~m} 2$ \\
\hline 870003 & work dav & $52,665.94$ & 0.004 & 250.000 & 1.000 & $210.66 \mathrm{HR}$ \\
\hline$-01 T 10402010203$ & Frame Truss Deck-Rebar & 63.94 & 2.000 & 0.500 & 1.000 & 127.87 Ton \\
\hline 870002 & work day & 127.87 & 1.000 & 1.000 & 1.000 & $127.87 \mathrm{HR}$ \\
\hline A-ST-20.15.00 & A-ST-20.15.00-Core Tube Shear Wall & $8,618.74$ & 1.000 & 1.000 & 1.000 & $8,618.74 \mathrm{m3}$ \\
\hline$-01 T 10402010301$ & Core Tube Shear Wall-Concrete & $8,618.74$ & 1.000 & 1.000 & 1.000 & $8,618.74 \mathrm{~m} 3$ \\
\hline 870001 & work dav & $8,618.74$ & 0.429 & 2.331 & 1.000 & $3,697.44 \mathrm{HR}$ \\
\hline$-01 \mathrm{~T} 10402010101$ & Core Tube Shear Wall-Jumping Formwork & $23,972.30$ & 1.000 & 1.000 & 1.000 & $23,972.30 \mathrm{~m} 2$ \\
\hline 870022 & work dav & $23,972.30$ & 0.000 & $2,994.012$ & 1.000 & $8.01 \mathrm{HR}$ \\
\hline$-01 \mathrm{~T} 10402010201$ & Core Tube Shear Wall-Rebar & $2,585.62$ & 1.000 & 1.000 & 1.000 & 2,585.62 Ton \\
\hline 870021 & work dav & $2,585.62$ & 0.500 & 2.000 & 1.000 & $1,292.81 \mathrm{HR}$ \\
\hline
\end{tabular}


Fig. 10. Classification system of Z14 towers project

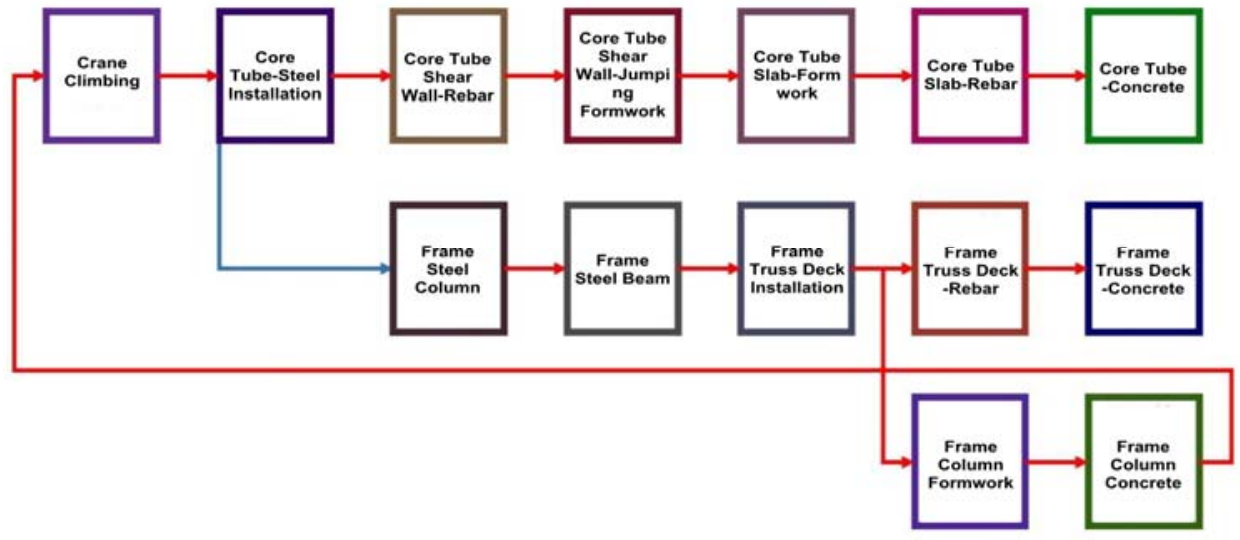

Fig. 11. Tasks generated and logics between tasks

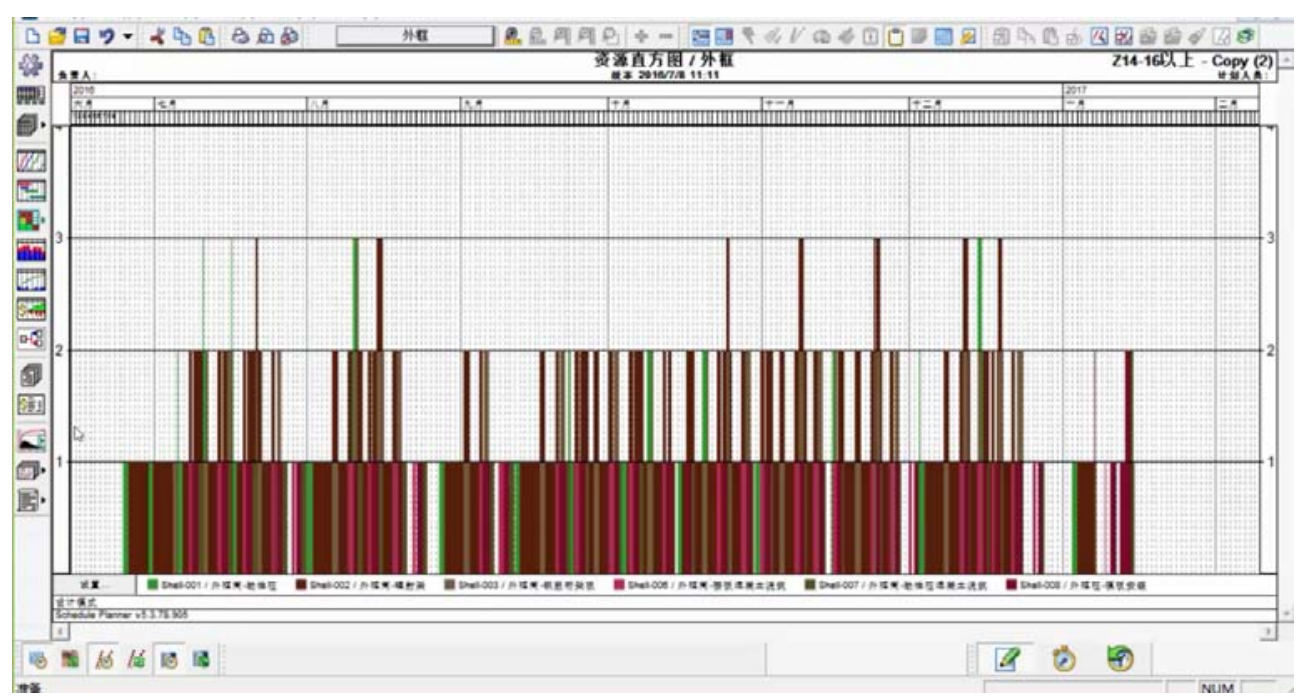


Fig. 12. Resource distribution based on BIM model

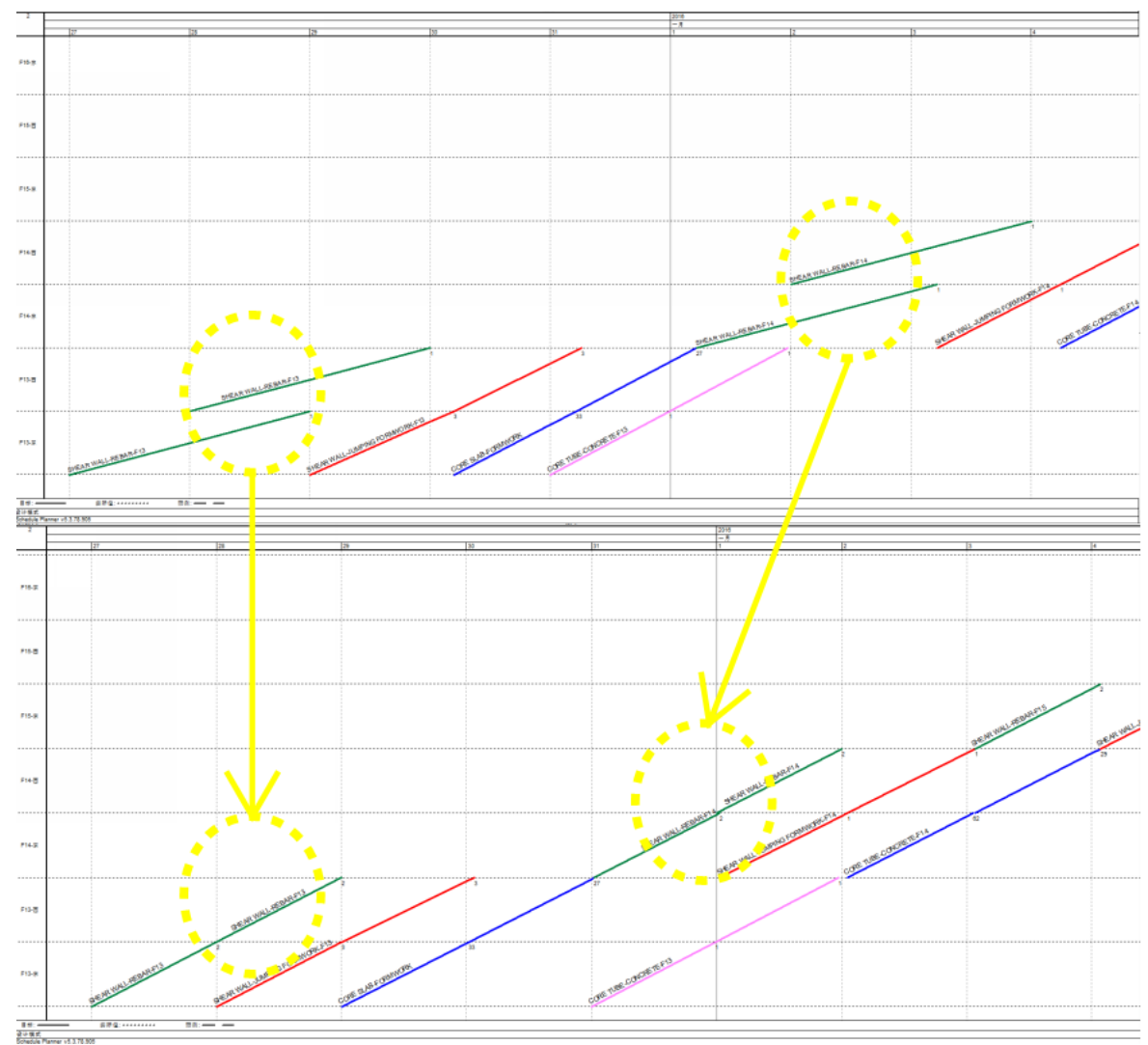

Fig. 13. Schedule optimization by using BIM and flowline method

Schedule Planner uses flowline method [9] to represent the schedule, the schedule based on BIM model tasks, quantities, location and productivity, makes it easy for contractor to illustrate the schedule to owners and trades by tasks logistics and resource distribution (Figure 12), more than just a schedule simulation. Take the reinforcement steel activity for example, from the BIM model based schedule, project team found an overlap of rebar labors between two locations, by adjusting the resources, optimize the distribution to minimize the schedule waste (Figure 13).

By collecting actual productivity rates on jobsite, project team produces the forecast schedule based on calculated remainning quantities from a BIM model and actual productivity. For example, if a task's starting data is behind the scheduled day, the contractor can change the productivity rates according to the actual activity and associated quantities which is from the BIM model, then forecast the finished date. This is one of the significant benefits by using BIM as a tool for scheduling. 


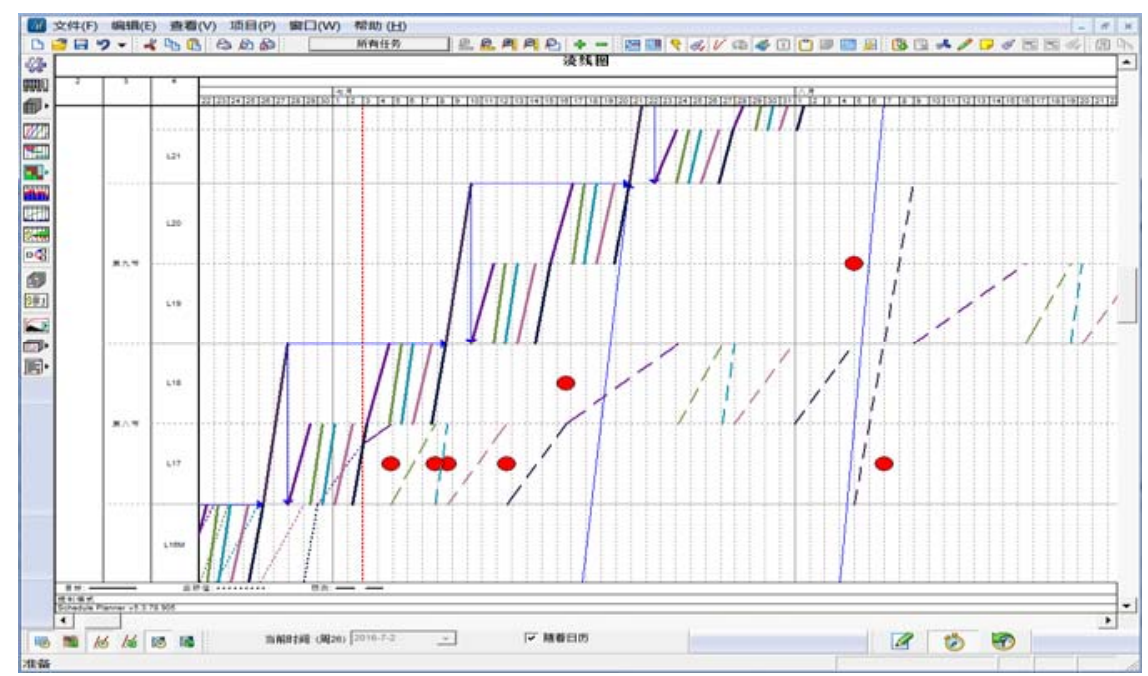

Fig. 14. Schedule predicting based on actual productivity and BIM information

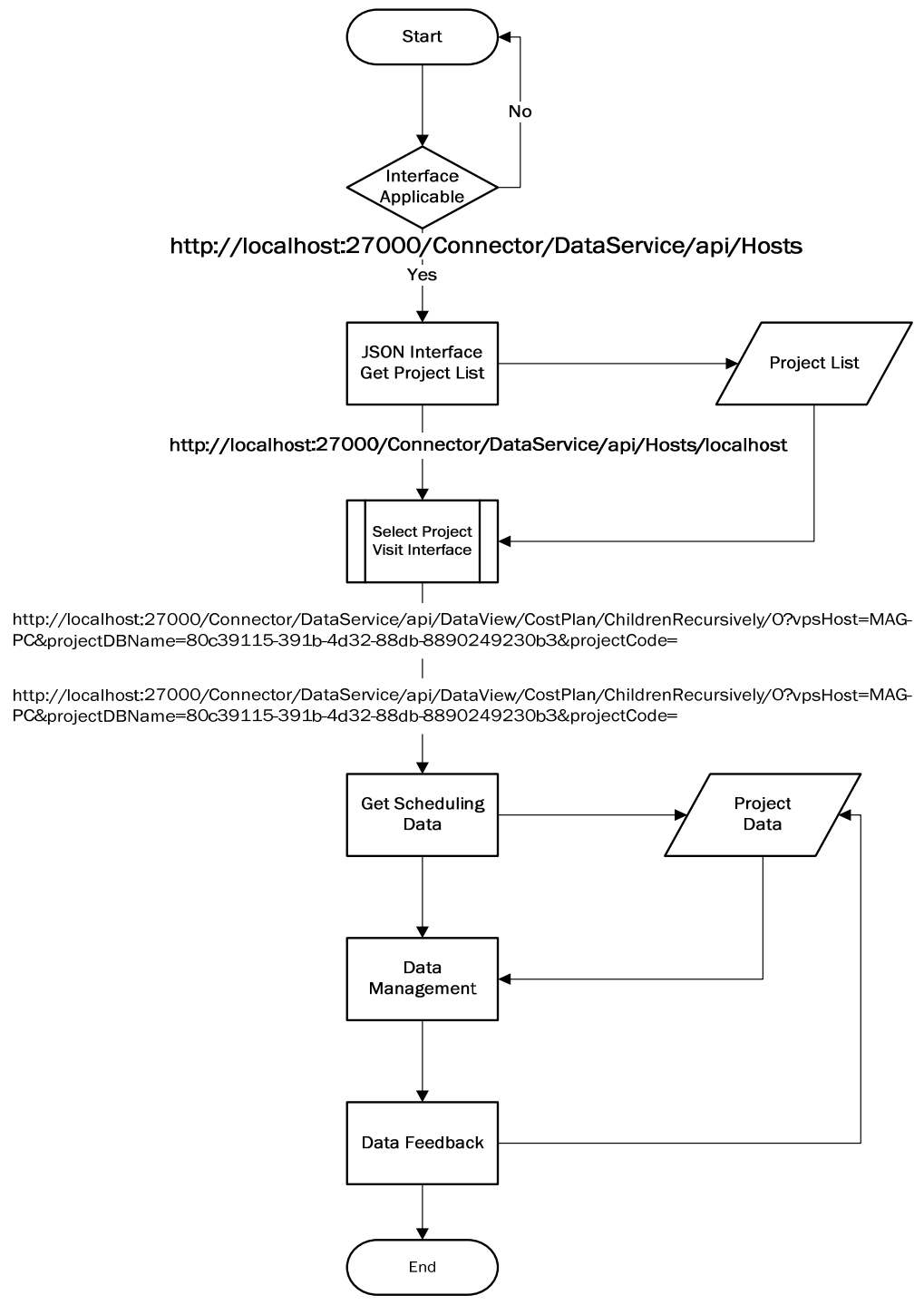

Fig. 15. Data management process

Data management. The project team use classification system as an ID for a building element, based on the ID address, all actual productivity data is documented during construction. Through the API of schedule software, project team extract the data as XML format by JavaScript Object Notation. 
The construction intermittent productivity data and unusual data that are caused by emergent situation (e.g., suspension of work caused city environmental haze warning) will be filtered by setting data criteria. So a comprehensive productivity rate for each task will be calculated and import back to schedule database. For a similar project in future, after extract BIM model to schedule software, besides generating a schedule's tasks based on classification, the duration will also be calculated based on model quantities and productivity database.

In addition, the construction diary information is also exported along with every day's actual productivity. During the construction process of similar project in future, the data will serve as an experience reference, to prevent the schedule delay and low productivity.

\section{Conclusions}

This paper outlines how to use BIM as a tool for scheduling and data management. Sharing information using the BIM model provides a work platform used by project teams, and using BIM as a source of all project information could allow project team to make the best decisions earlier in the project process.

The method of scheduling process can be applied to most schedule software, as more and more schedule software have add-ons for BIM model now, including Asta Powerproject, Innovaya Visual $4 \mathrm{D}$, etc. And the method of using BIM based classification system as a building component's Internet Protocol to document, analyze and manage the productivity data generated from scheduling execution, can also be applied all kinds of data information, making the information more valuable for similar project in future, and can be served as a basis for BIM big data technology.

\section{References}

[1] Information on http://cadsoft-consult.com

[2] Chuck Eastman, Paul Teicholz, Rafael Sacks and Kathleen Liston, BIM Handbook, A Guide to Building Information Modeling for Owners, Managers, Designers, Engineers, and Contractors, second ed., John Wiley \& Sons, Hoboken, 2011, pp.281-282.

[3] Hojjat Adeli, Asim Karim, Construction Scheduling, Cost Optimization and Management, Spos Press, New York, 2003, pp.54

[4] Information on http://usa.autodesk.com/building-information-modeling/

[5] Ofer Zwikael, John Smyrk, Project Management for the Creation of Organisational Value, Springer Publishing, New York, 2011,pp.196

[6] Booz, Allen \& Hamilton, Earned Value Management Tutorial Module 2: Work Breakdown Structure, in: U.S.DOE Office of Science, Tools \& Resources for Project Management, Washington DC, 2011.

[7] Chuck Eastman, Paul Teicholz, Rafael Sacks and Kathleen Liston, BIM Handbook, A Guide to Building Information Modeling for Owners, Managers, Designers, Engineers, and Contractors, second ed., John Wiley \& Sons, Hoboken, 2011, pp. 282.

[8] Jerry Laiserin, Presented at the Fourth International Technical Symposium on the Application of BIM Technology in Design, Construction and Real Estate Enterprise Collaborative Work, Beijing, 2014

[9] Olli Seppänen and Russell Kenley, Location-Based Management for Construction Planning, scheduling and control, Spon Press Publishing, London, 2010 